\title{
Active and reactive power sharing in micro grid using droop control
}

\author{
Omar Feddaoui $^{1}$, Riad Toufouti ${ }^{2}$, Labed Djamel ${ }^{3}$ \\ ${ }^{1,3}$ Department of Electrical Engineering University Constantine, Algeria \\ ${ }^{1,2}$ Department of Electrical Engineering, Laboratory of electrical and renewable energies LEER, \\ Souk Ahras University, Algeria
}

\begin{tabular}{l} 
Article Info \\
\hline Article history: \\
Received Apr 9, 2019 \\
Revised Nov 7, 2019 \\
Accepted Nov 25, 2019 \\
\hline
\end{tabular}

\section{Keywords:}

Active and reactive

Droop control

Intelligent power systems

Power controller

Renewable energies

Smart grid

Voltage inverters

\begin{abstract}
The development of renewable energy contributes to the global objectives of reducing our greenhouse gas emissions, obtaining and increasing our energy efficiency. In the face of these changes, the electric-network must adapt, while maintaining a high level of reliability and a quality of energy production. To meet this objective, it is recommended to use highly developed electrical network by integrating renewable energy sources in order to adapt the energy consumption to their production, using electrotechnical software information and telecommunications technologies. We are talking about intelligent grids (Smart Grid). The main objective of the work presented in this paper is the contribution to the study of intelligent network for efficient management of energy produced by several sources linked to the AC bus via the voltage inverters. Numerical simulations have been presented to validate the performance of the proposed active and reactive power controller (Droop Control).
\end{abstract}

Copyright $(0) 2020$ Institute of Advanced Engineering and Science. All rights reserved.

\section{Corresponding Author:}

Riad Toufouti,

Department of Electrical Engineering,

Souk Ahras University,

Annaba Road, 410001 Souk ahars Algeria.

Email: riad.toufouti@univ-soukahars.dz

\section{INTRODUCTION}

At present-day there are many problems with the operation of electricity transmission in distribution networks. The major one concerns the use of fossil energy sources which have a direct effect on the evolution of carbon dioxide emission [1,2]. For that, a new renewable energy integration projects are the most common solution to meet the global goal to reduce our greenhouse gas emissions and to obtain and increase our energy production efficiency from renewable energy sources [3]. However, in face of these changes, the electricity grid must adapt to transport the production power of renewable energies, which are by nature variable and intermittent, while maintaining a high level of reliability and a quality of supply [4-6]. To meet this goal, it is recommended to use predictive devices for a better management power system presented as smart grids (SG) [4]. SG is an emerging solution to these problems, its not only a power grid that integrates centralized or distributed power generation, but also has production resources came from renewable energies [6-10]. By adding two-way communication and new information and communication technology strategy, we can build an intelligent energy management system [10], It offers new perceptive both in production and consumption of power. However, the advantages of this communication tenchniques in voltage and frequency control, the problem persists in security matter and the vulnability of main structure in case of cutting links that connect the communicative blocks from each other [11]. The solution for this problem is the implementation of local control methods (droop control) which assure the stability of SG in all 
circumstances, it is responsible for the reliability and improves performances for the entire system without any communication between disctributed generator units $[12,13]$.

In this paper we present in first part the general structure of intelligent networks, its principle of functioning, later in the second part we will present one of the main contributions of SG for an efficient management of active and reactive power by a technique based on local control using inverters at the interconnection bridge of several sources (Droop Control). Subsequently, numerical simulations are presented to validate the performance of this controller for changing the active and reactive power while maintaining a stable frequency and voltage to the load demand.

\section{TO AN INTELLIGENT POWER ELLECTRICAL NETWORK}

2.1. Conventional power electric network

The traditional power grid is the main grid assuring the transmission of electrical energy from the production power system to the consumers. It includes production generators, transformers, transmission lines, compensation systems, protection devices and finally the consumer Figure.1. An electrical network must also guarantee the dynamic regime of the production-transport-consumption, implementing adjustments to ensure the stability of the system [3,7]. The same network presents problems related to the energy produced that is dependent on coal and oil (greenhouse gases), it is even centralized in one place (high transport cost). To overcome these major problems, the governments involved in the Kyoto Protocol must multiply their actions in renewable energy production [1-3]. At present day, several electrical networks include hybrid systems based in renewable energy resources such as wind, solar, etc...

However, in view of the massive development of renewable energies and their integration into the conventional networks, a large amount of energy produced cannot be fully stored due to the dimensioning problem and the cost of the batteries [5]. It is interesting to manage this energy in an efficient and intelligent way, for that the electrical network must developed into SG $[6,10]$. The agreement reached by the COP (Conferences of the Parties) on 21/12/2015 marks the wish of many countries and electricity markets that regard Smart Grids as an obligation and as advanced solutions to improve certain performances like safety, reliability, energy quality, energy costs, and optimization of demand with energy efficiency [9].

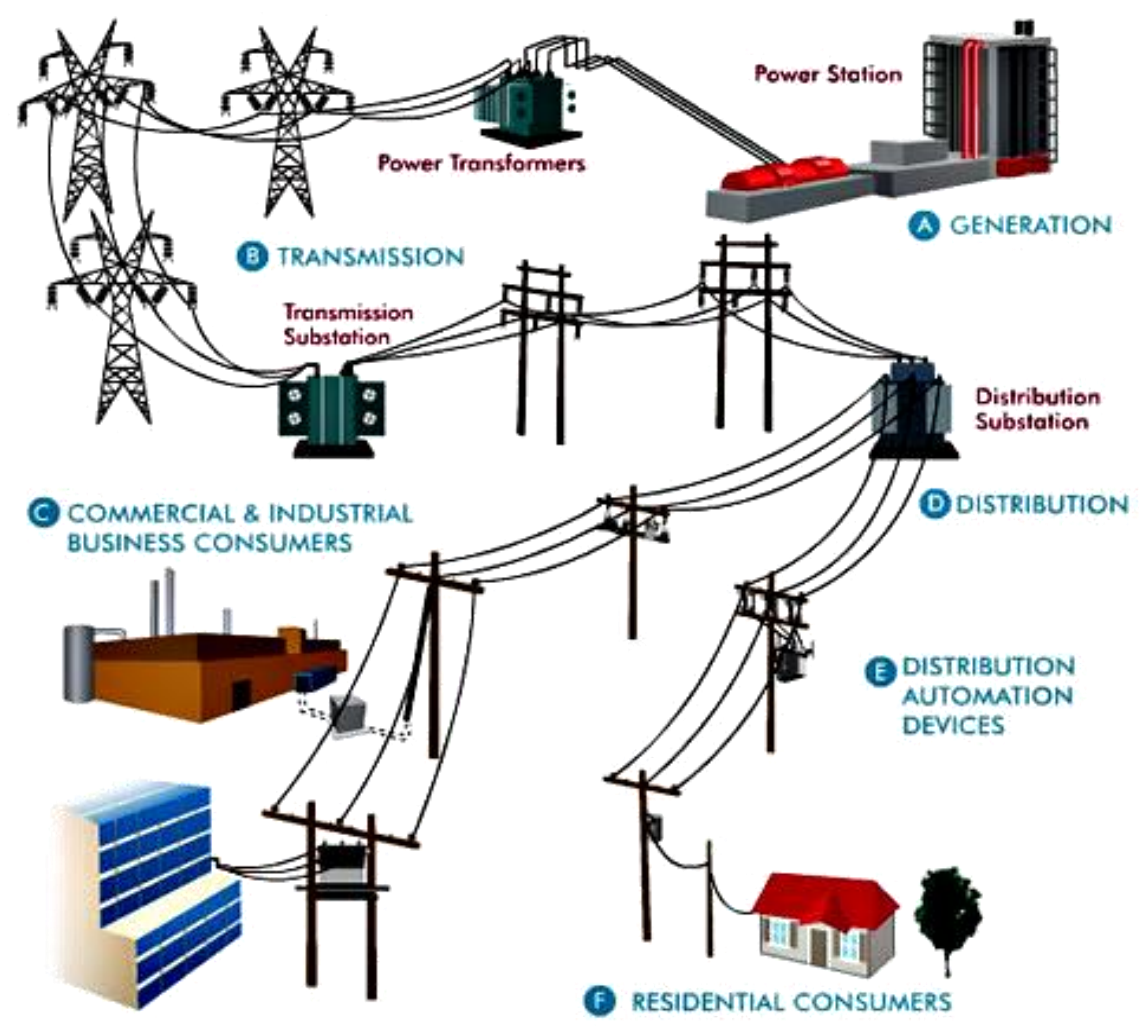

Figure 1. Structure of the conventionnel electric network 


\section{INTELLIGENT POWER ELECTRIC NETWORK}

SG is an electricity distribution network that uses computer technologies to optimize and coordinate electricity generation, distribution and consumption to improve energy efficiency and reliability [9, 10]. The SG manages the power generation by using remote monitor in control that is considered as an intelligent node where using Supervisory Control and Data Acquisition (SCADA) or Advanced Metering Management (AMI). Generally SG is operated as transmission and distribution network. Another operation of SG involves smart homes and intelligent building through a smart meter to microgrids (MG), household and electrical vehicles....etc [14]. Figure 2, shows a compact outlook structure of integrated renewable energy system that merges internet and grid features. This system has a SG with a power sources, a data response, and a load control center such as a residential home [15]. The role of a local control center is to keep statistics of power generation and consumption and respond to users' requests in an optimized manner. If consumers within the network require more energy than usual demand and don't want to involve grid, they can make request to local control center and can get required energy if available [16]. These new technologies will make it possible to save money by smoothing peaks of consumption by using decentralized production units and reduce calls for loads that are costly and more polluting. In this way the power supply system will be more reliable and the cost of electrical energy could be reduced.

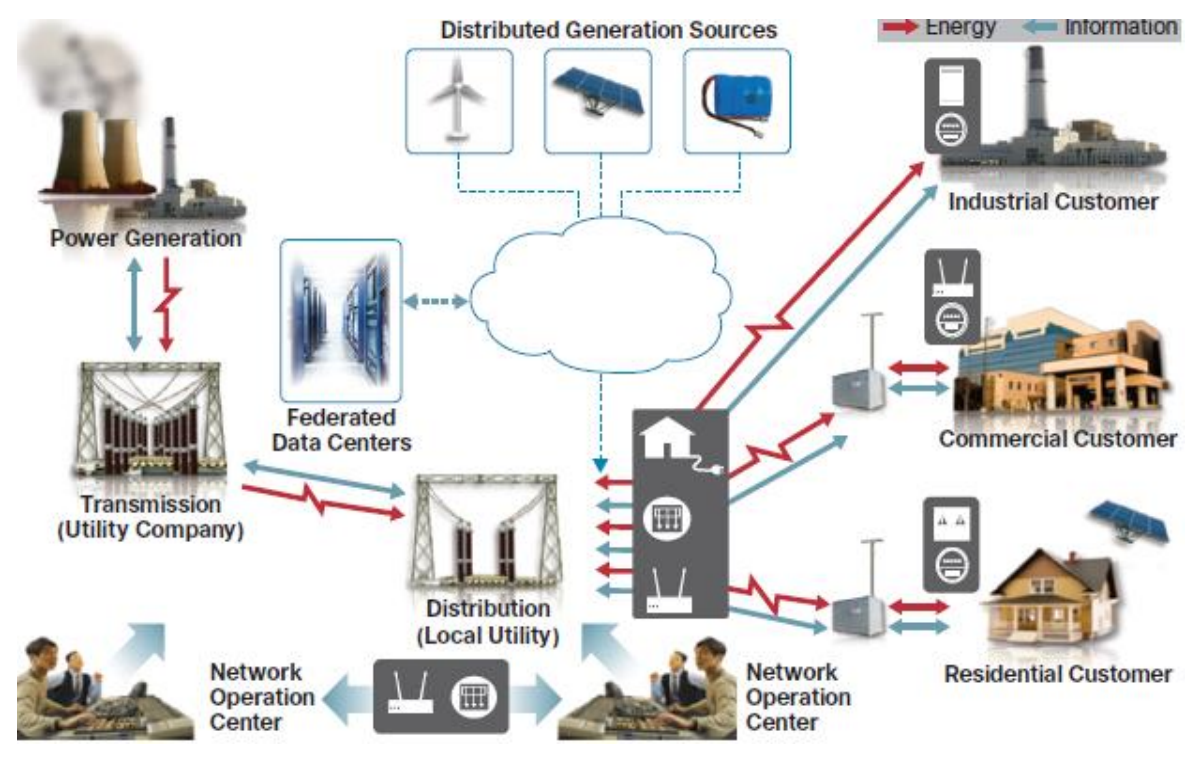

Figure 2. Structure of SG [9]

\subsection{Objectives by SG}

The objectives of SG applications are multiple. The adjustment of electricity flows between suppliers and consumers is the most important. Each consumer is an element of this intelligent network, he can participate in production or consumption of energy according to his needs, so the consumer can decide to purchase or sale this energy.The MG forming the SG can adjust their production according to consumer demand. They will be able to support the public distribution network in more efficiently way during peaks in demand with the use of information and communication technologies [17].

\subsection{The technical-economic challenges of SG}

Despite of many advantages of SGs, they present technical and economic challenges. How can we find a solution to the size and price of today's storage technologies? Most of these MGs will not be able to produce and store enough energy to connect with the grid $[3,9]$. The management of SG and their connection to the conventional grid is complex, and generally these systems use voltage and frequency control strategies to ensure system stability [18]. However, these technologies are not always suitable for all types of renewable energies. Moreover, the power production from each source is not taken account according to the demand and their respective capacity. This last challenge is currently the subject for several research projects which are currently focusing in the implementation of new control techniques for the paralleling operation of inverters to do management of this decentralized production sources, this is the objective of our work. 


\subsection{Control Techniques on smart power system}

Several research papers have been published by many laboratories to identify the impacts of decentralized production by renewable energies on the stability of SGs [19]. These studies have shown that some challenges remain in the stability of MG following the massive integration of renewable energies in the system [5]. The general structure of a MG is showed in Figure 3. Generally it is a small SG. It includes a photovoltaic system, a wind system and an energy storage system (example of structure). Each source is connected to the AC bus via an electronic converter. The three-phase network is interfaced with the AC bus using the main switch $[4,20]$. The Droop control as distributed primary control introduce a perfect solution for parallel operation inverters. It consists as a functioning control system based on behavior of synchronous generators, where $\mathrm{P}$ and $\mathrm{Q}$ are the active and reactive powers, influencing respectively on frequency and voltage values. In the next paragraph, we introduce our droop control unit for a study of multisource generator system in multiple cases of load demand changes.

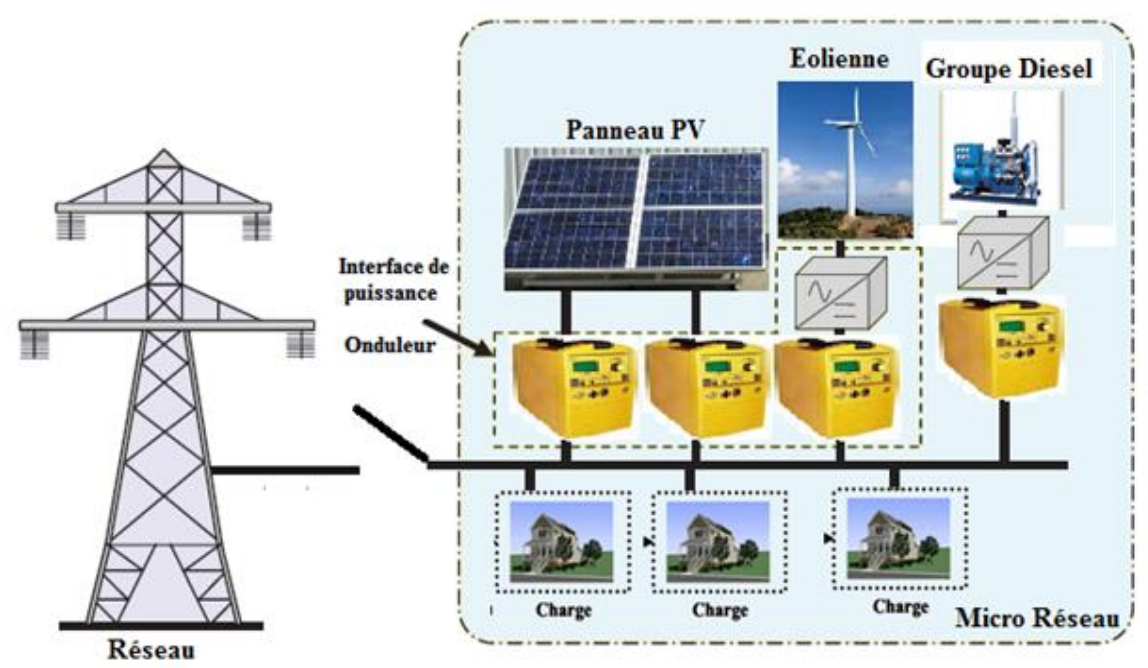

Figure 3. Structure of Micro-Grid based renewable energy [20]

\section{DROOP CONTROLLER SYSTEM}

There are two categories of methods or techniques for controlling these networks in power sharing mode $[4,21,22]$ :

- Methods using centralized control.

- Methods using local control.

Centralized control methods are techniques that use a SCADA and the second is power sharing techniques based on a master-slave configuration [4]. The methods that use local control are designed to share the power of the various production sources interconnected to the AC bus via the control of the inverters connected in parallel $[23,24]$. Several approaches have been proposed, such as Droop Control, which is the most used. In our study, we will use this droop controller for a detailed study. Unlike local controllers, the classic active and reactive power droop allows for power sharing without necessarily requiring a communication link between the control points. Because of its simplicity, Droop Control is the most widely used technique in several research projects for the control of parallel sources, when the power demand by load increases, the controller gives the order to the generators to vary their frequencies, which produces an acceleration or a slowing down of the rotary machine due to the inertia of the system.[3]. A micro-network as shown in Figure 4 is assumed which includes production sources connected to the PCC point. The droop controller is based initially on this consideration. Figure 5 gives the equivalent diagram of the system (source-line-point PCC). It is possible to define a relationship between the reactive power with the voltage level and between the active power and the frequency of the system. In (1) and (2) [3, 4]:

$$
P=\frac{V_{i n v} V_{g}}{X_{L}} \sin (\delta)
$$




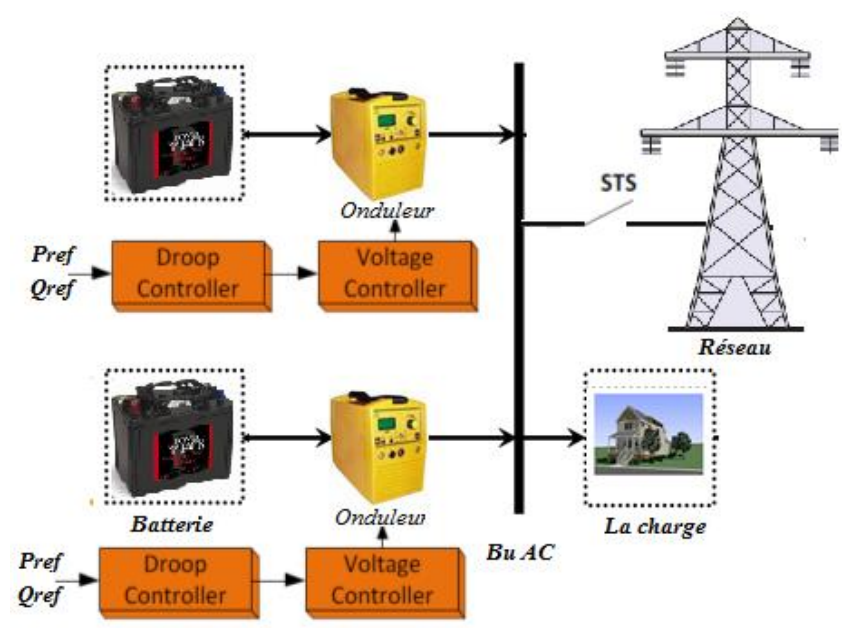

Figure 4. Micro-Grid based Droop Control technique [25]

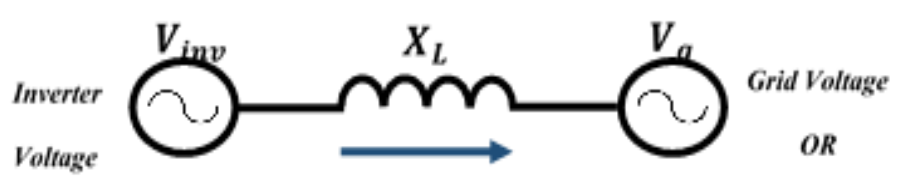

Figure 5. Droop Control for two-voltage source inverter [25]

$\delta$ represents the voltage phase generated by the inverter $V_{\text {inv }} . \mathrm{X}_{\mathrm{L}}$ is the impedance between $\mathrm{V}_{\text {inv }}$ and the voltage at the interconnection node $\mathrm{V}_{\mathrm{g}}$. If $(\square \rightarrow 0)$, $\sin (\square) \approx \square$ therefore the active and reactive powers are given by:

$$
\begin{aligned}
& P=\frac{V_{i n v} V_{g} \delta}{X_{L}} \\
& \delta=\int\left(\omega_{i n v}-\omega_{g}\right) \\
& Q=\frac{V_{g}\left(V_{i n v}-V_{g}\right)}{X_{L}}
\end{aligned}
$$

these equations show the link between the active power and the phase angle and between the reactive power and the voltage level. However, low-voltage lines are normally more resistive, and it would be more appropriate to define a relationship between reactive power with phase angle and active power with voltage level $[4,25]$.

The pulsation of frequency $(f)$ and the level of voltage $(V)$ are given by:

$$
\begin{aligned}
& f=f_{0}-k_{\omega} \cdot\left(P-P_{0}\right) \\
& V=V_{0}-k_{\nu} \cdot\left(Q-Q_{0}\right)
\end{aligned}
$$

where:

$f_{\mathrm{o}}$ and $\mathrm{V}_{0}$ : Nominal values of frequency and voltage level of MG system.

$\mathrm{K}_{\mathrm{w}}$ and $\mathrm{K}_{\mathrm{v}}$ : Droop coefficients of displacement.

$\mathrm{P}_{0}$ and $\mathrm{Q}_{0}$ : Active and reactive power values equivalent to the nominal values of the micro-grid voltage. 
Figure 6 shows graphically the principle of displacement used in the Droop controller [20]. A simplified schematic diagram of the active and reactive powers is shown in Figure 7. The first block calculate the active and reactive powers of the source $(\mathrm{P}, \mathrm{Q})$, a second block generates the frequency and reference voltage values using the previous equations of the droop control, a third block generates three sinusoidal signals, they are transformed into two-phase reference voltage $V_{\text {dref }}$ and $V_{\text {qref }}$. These two voltages values are introduced into the control unit which comprises four loops two for regulating the voltages and the others for regulating the currents, after that we have to switch mode to get the three sinusoidal signals of references. These voltages values are compared with a triangular signal in the MLI block (triangular sine) to generate pulses to the inverter. In this way, the active power of each source can be controlled by varying the frequency (phase angle) and the reactive power can be regulated by varying the amplitude of the output voltage in the inverter [4].
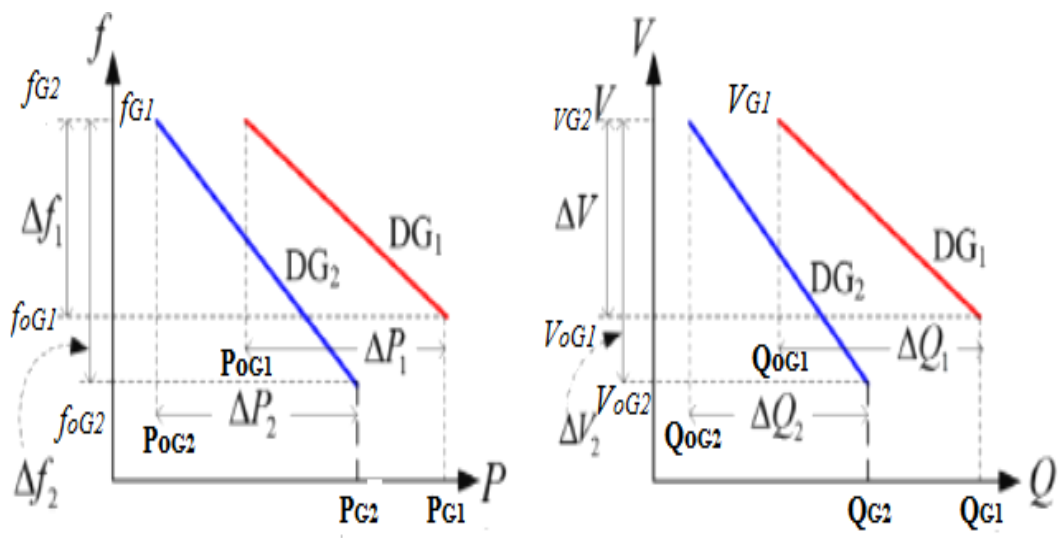

Figure 6. Principale of Droop Control technique

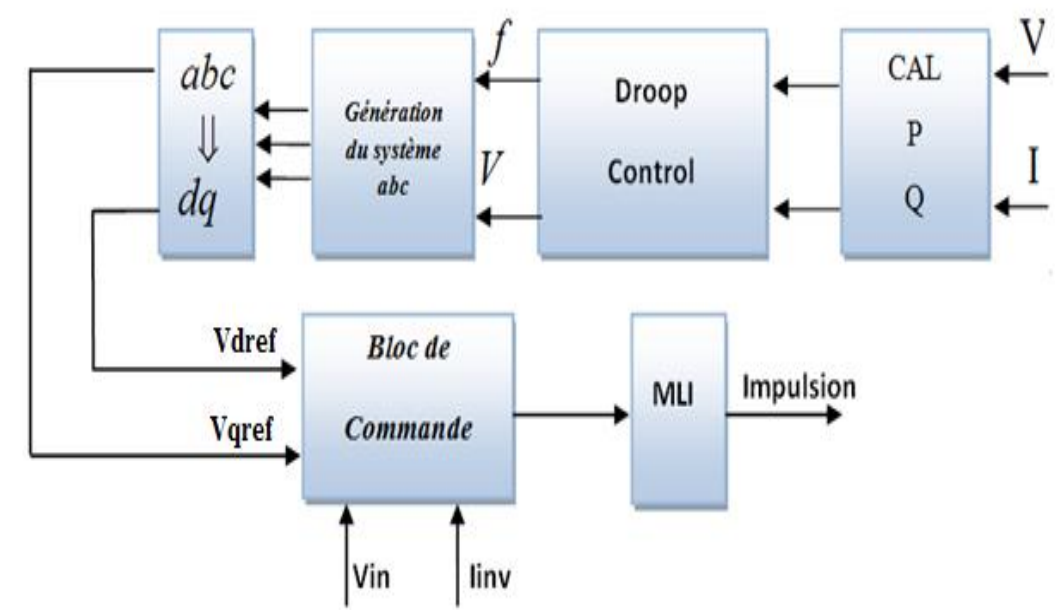

Figure 7. Simplified diagram of droop control technique

In the next, numerical simulations will be presented of active and reactive power sharing between three sources which are linked to the AC bus by power interfaces (voltage inverters). For our study we are very interested in photovoltaic sources considering their major potential in Algeria. It has been assumed that the sources supplying the three inverters with a direct voltage obtained directly from photovoltaic panels. The structure system is represented in Figure 8. We perform two simulation tests, the first for a variable load in isolated MG mode and the second for a variable load in connected mode to the network with given time of connection. 


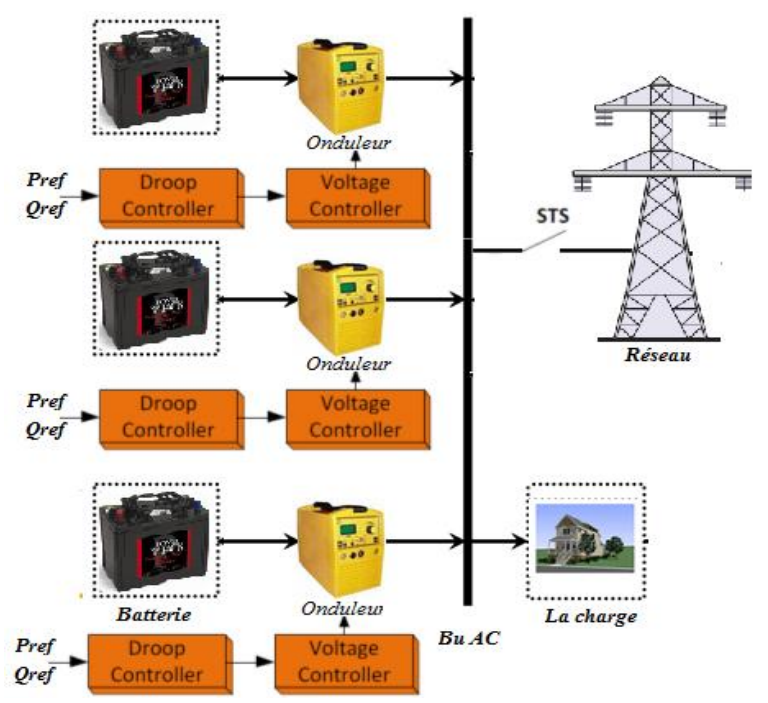

Figure 8. Proposed structure of droop control [25]

\section{SIMULATION RESULT}

In the next, numerical simulations is operated in an isolated-mode, with an initial load of $1000 \mathrm{~W}$ active power and $100 \mathrm{VAR}$ reactive power, at the instant $0.6 \mathrm{~s}$ the load increase to $4000 \mathrm{~W}$ for active power and 400 VAR for reactive power. From Figure 9, we observe that the frequency is maintaining stable in $50 \mathrm{~Hz}$ (nominal frequency), where the difference between the frequency of voltage generated by each inverter and the nominal frequency is almost zero in both transient and study state, even in load power variations $1000 \mathrm{~W}$ to $4000 \mathrm{~W}$, the frequency is $49.98 \mathrm{~Hz}$.

From simulation results, we remark a good tracking performance of the reference voltage generated by the power controller as shown in Figure 10. Despite where there has an increase in the load from 1000W to $4000 \mathrm{~W}$ at time $\mathrm{t}=0.6 \mathrm{~s}$, the difference between these voltages is negligible $(\Delta \mathrm{V}=0.06 \mathrm{~V})$, is shown that the magnitude of output voltage and frequency has been stable in allowable limit under proposed control strategy as shown in Figure 11. The power sharing between the three generators shared the real power and reactive power accurately as the output power of loads shares between other DGs based on droop coefficients. If the load power increases from $1000 \mathrm{~W}$ to $4000 \mathrm{~W}$, the power sharing curve of the three voltage source inverter will also change as shown in Figures 12 and 13. However, the load current has increase from 5A to 25A as shown in Figure 14 and the inductor currents of the three inverters after taking away the switching ripples with the LC filter.

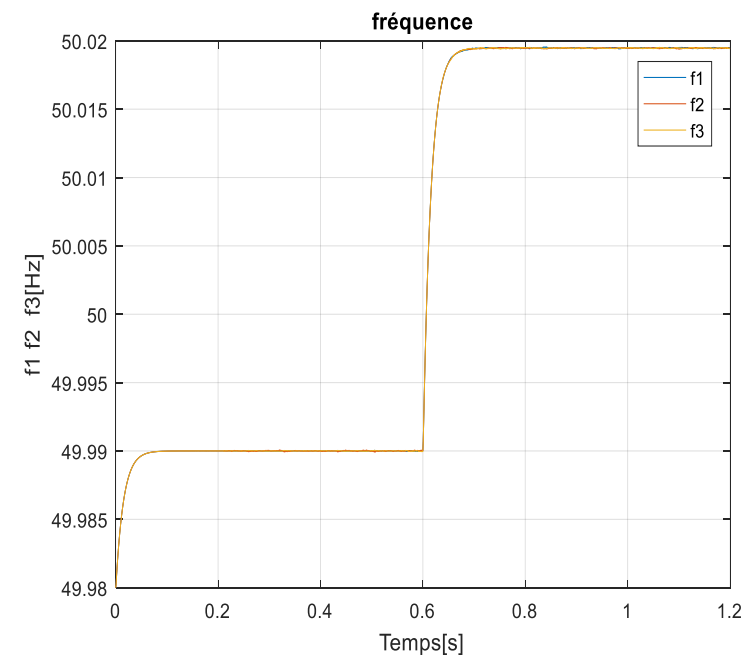

Figure 9. Frequency of three voltage sources inverter

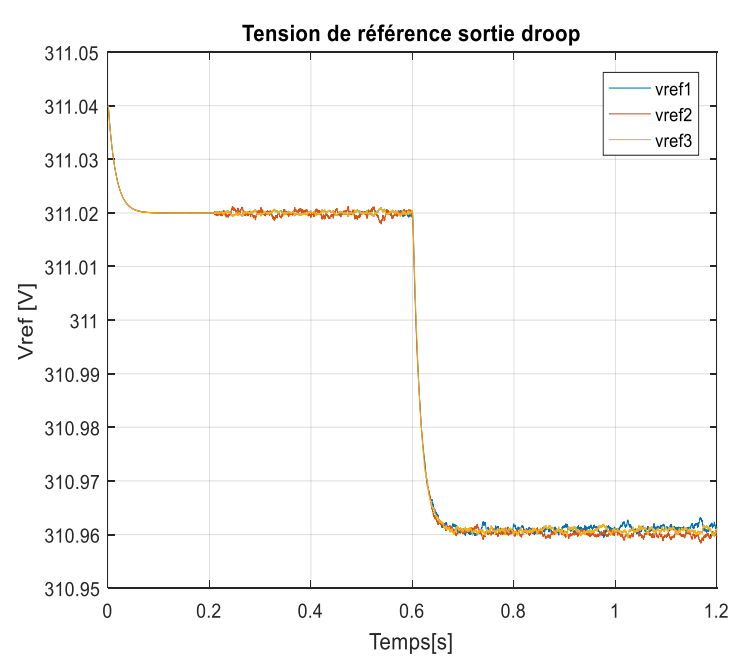

Figure 10. Magnitude of load voltage 


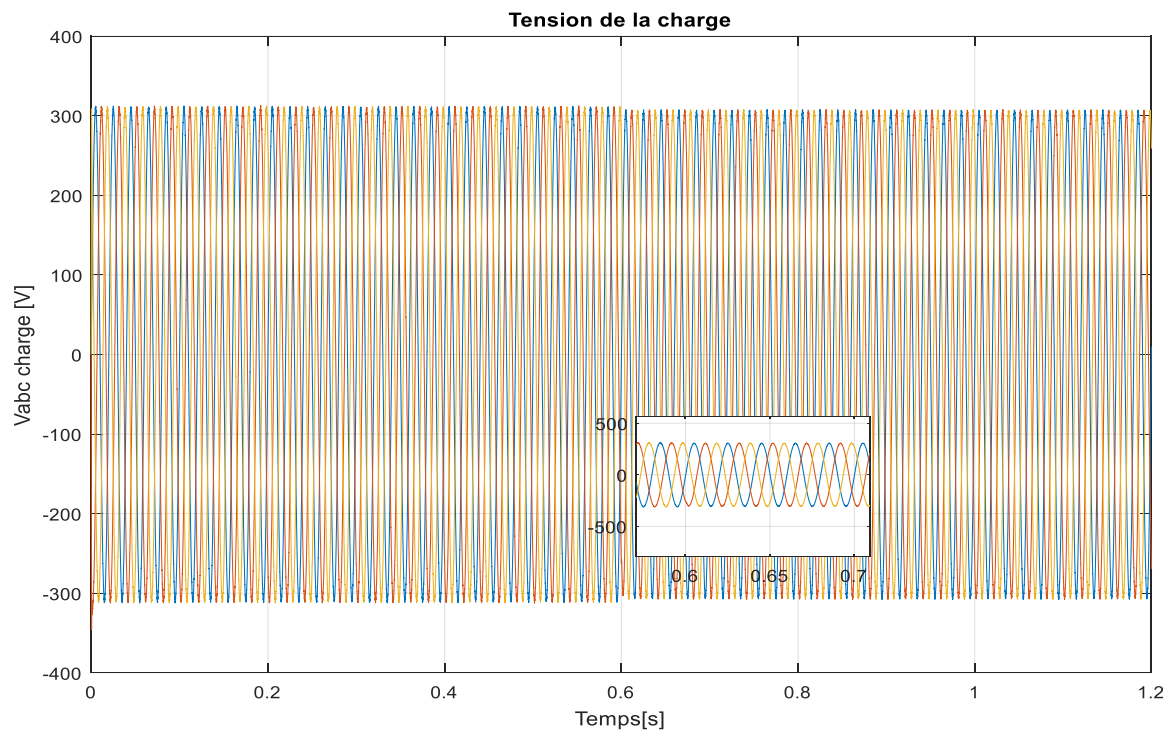

Figure 11. Waveforms of the load voltage

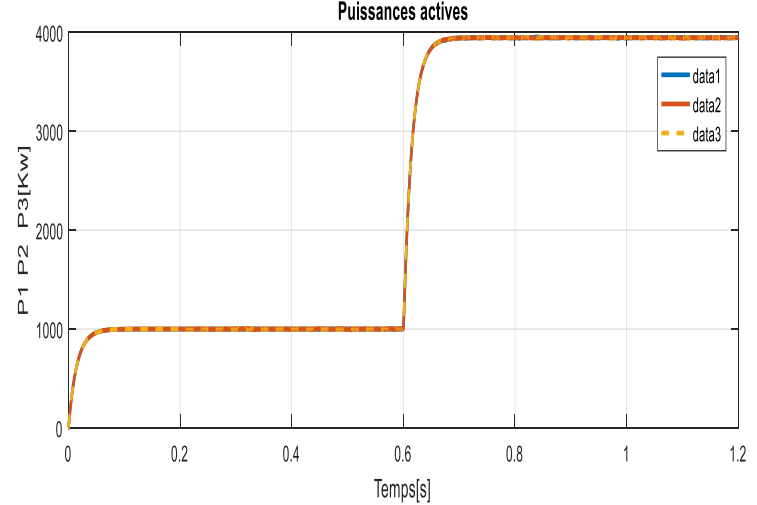

Figure 12. Active power of three voltage sources inverter

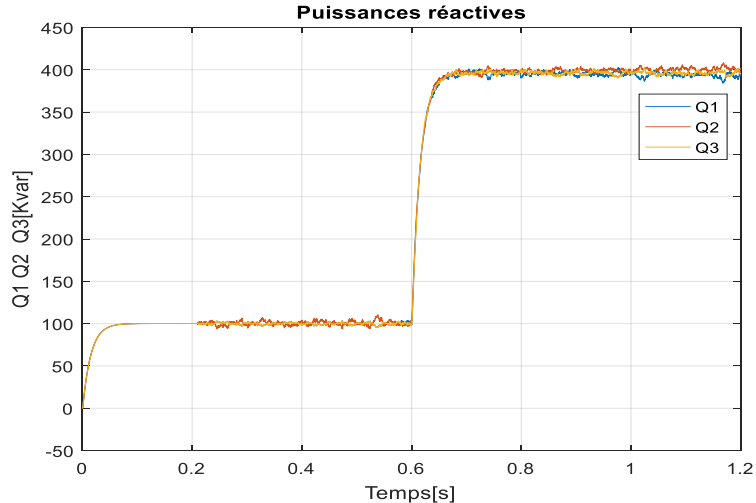

Figure 13. Reactive power of three voltage sources

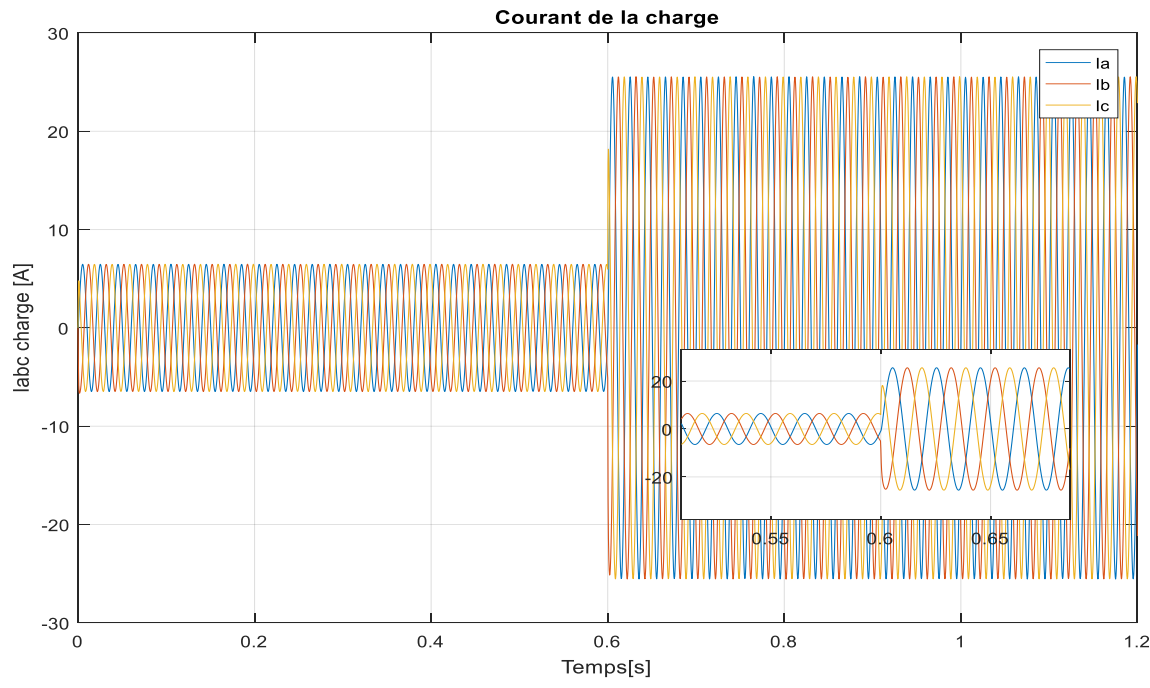

Figure 14. Inverter Load courants 


\section{CONCLUSION}

A new method for controlling voltage and frequency in islanded and connected grids using parallel inverters is presented. In this paper specialy, a droop control technique for three parallel voltage source inverters is proposed, using P-f \& Q-V droop control for sharing the load power with a stable voltage and frequency. From the results obtained it can be noted that the proposed P-f \& Q-V droop control scheme provides an excellent decouple control of flux and speed compared to the conventional control scheme with respect to changes in active power and reactive power. Two experiments are included to show the described behavior, considering the mitigation of voltage and frequency harmonics.

\section{REFERENCES}

[1] C. S. AN, T. Hashiguchi, and T. Goda, "Control scheme of hybrid wind-diesel power generation system," in From Turbine to Wind Farms-Technical Requirements and Spin-Off Products, ed: IntechOpen, 2011.

[2] R. Sebastian, M. Castro, E. Sancristobal, F. Yeves, J. Peire, and J. Quesada, "Approaching hybrid wind-diesel systems and Controller Area Network," in IEEE 2002 28th Annual Conference of the Industrial Electronics Society. IECON 02, Sevilla, vol.3, pp. 2300-2305, 2002.

[3] A.-M. Imokrane, "Intégration des commandes de statisme aux sources d'énergies renouvelables décentralisées," École de technologie supérieure, 2015.

[4] C. Guzman, "Étude de topologies et gestion d'un système d'énergies renouvelables multisources," Université du Québec à Trois-Rivières, 2013.

[5] H. Kanchev, "Gestion des flux énergétiques dans un système hybride de sources d'énergie renouvelable: Optimisation de la planification opérationnelle et ajustement d'un micro réseau électrique urbain," Ecole centrale de Lille, 2014.

[6] S. Bouckaert, "Contribution des Smart Grids à la transition énergétique: évaluation dans des scénarios long terme," 2013.

[7] C. W. Gellings, "The smart grid: enabling energy efficiency and demand response," The Fairmont Press, Inc., 2009.

[8] Carvallo and J. Cooper, "The advanced smart grid: Edge power driving sustainability," Artech House, 2015.

[9] S. M. Malik, X. Ai, Y. Sun, C. Zhengqi, and Z. Shupeng, "Voltage and frequency control strategies of hybrid AC/DC microgrid: a review," IET Generation, Transmission \& Distribution, vol. 11, pp. 303-313, 2017.

[10] Y. Yoldaş, A. Önen, S. Muyeen, A. V. Vasilakos, and İ. Alan, "Enhancing smart grid with microgrids: Challenges and opportunities," Renewable and Sustainable Energy Reviews, vol. 72, pp. 205-214, 2017.

[11] H. R. Baghaee, M. Mirsalim, G. B. Gharehpetian, and H. A. Talebi, "A decentralized power management and sliding mode control strategy for hybrid AC/DC microgrids including renewable energy resources," IEEE Transactions on Industrial Informatics, 2017.

[12] Y. Sun, X. Hou, J. Yang, H. Han, M. Su, and J. M. Guerrero, "New perspectives on droop control in AC microgrid," IEEE Transactions on Industrial Electronics, vol. 64, pp. 5741-5745, 2017.

[13] C. Dou, Z. Zhang, D. Yue, and M. Song, "Improved droop control based on virtual impedance and virtual power source in low-voltage microgrid," IET Generation, Transmission \& Distribution, vol. 11, pp. 1046-1054, 2017.

[14] M. Hossain, N. Madlool, N. Rahim, J. Selvaraj, A. Pandey, and A. F. Khan, "Role of smart grid in renewable energy: An overview," Renewable and Sustainable Energy Reviews, vol. 60, pp. 1168-1184, 2016.

[15] J. Jin and W. Peng, "Development Partnership of Renewable Energies Technology and Smart Grid in China," in Sustainable Cities and Communities Design Handbook, ed: Elsevier, 2018, pp. 111-128.

[16] R. Zafar, A. Mahmood, S. Razzaq, W. Ali, U. Naeem, and K. Shehzad, "Prosumer based energy management and sharing in smart grid," Renewable and Sustainable Energy Reviews, vol. 82, pp. 1675-1684, 2018.

[17] E. Kabalci and Y. Kabalci, "Introduction to Smart Grid Architecture," in Smart Grids and Their Communication Systems, ed: Springer, pp. 3-45, 2019.

[18] C. Wan, J. Zhao, Y. Song, Z. Xu, J. Lin, and Z. Hu, "Photovoltaic and solar power forecasting for smart grid energy management," CSEE Journal of Power and Energy Systems, vol. 1, pp. 38-46, 2015.

[19] B. Schäfer, C. Grabow, S. Auer, J. Kurths, D. Witthaut, and M. Timme, "Taming instabilities in power grid networks by decentralized control," The European Physical Journal Special Topics, vol. 225, pp. 569-582, 2016.

[20] J. J. Justo, F. Mwasilu, J. Lee, and J.-W. Jung, "AC-microgrids versus DC-microgrids with distributed energy resources: A review," Renewable and Sustainable Energy Reviews, vol. 24, pp. 387-405, 2013.

[21] J. Kim, J. M. Guerrero, P. Rodriguez, R. Teodorescu, and K. Nam, "Mode adaptive droop control with virtual output impedances for an inverter-based flexible AC microgrid," IEEE Transactions on power electronics, vol. 26, pp. 689-701, 2010.

[22] M. Prodanovic and T. C. Green, "High-quality power generation through distributed control of a power park microgrid," IEEE Transactions on Industrial Electronics, vol. 53, pp. 1471-1482, 2006.

[23] K. Wang, X. Huang, B. Fan, Q. Yang, G. Li, and M. L. Crow, "Decentralized power sharing control for parallel-connected inverters in islanded single-phase micro-grids," IEEE Transactions on Smart Grid, vol. 9, pp. 6721-6730, 2017.

[24] J. Liu, Y. Miura, H. Bevrani, and T. Ise, "Enhanced virtual synchronous generator control for parallel inverters in microgrids," IEEE Transactions on Smart Grid, vol. 8, pp. 2268-2277, 2016.

[25] W. R. Issa, "Improved control strategies for droop-controlled inverter-based microgrid," 2015. 


\section{BIOGRAPHIES OF AUTHORS}

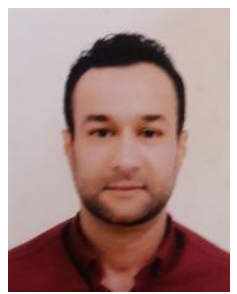

Omar Feddaoui : was born in Oran, Algeria, in 2011 received the Engineer degree from the University of Mohamed Cherif Messaadia Souk Ahras. Algeria. In 2014 received the M.S. degrees in electrotechnical, Option control of electrical machine. He is currently an Assistant Professor in Department of Electrical Engineering at Souk Ahras University, Algeria. His research interest includes on control of Hybrid Power System, and Microgrids.

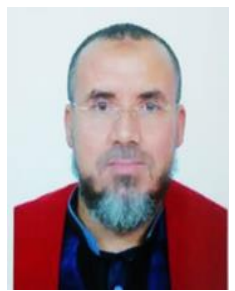

Riad Toufouti: received his Engineer, Master Doctorate and Professor degrees in Electrical Drive from the University of Constantine Algeria, respectively, in 1999, 2003, 2008 and 2017. Since 2003, he is currently a Professor of Electrical Engineering in Department of Electrical Engineering at Souk Ahras University, Algeria. His research interest includes on Electric Drives and Hybrid Power System, and Smart Grid.

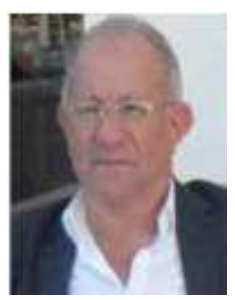

Djamel Labed is Director of electrical engineering laboratory Constantine LGEC, Director of Research. He received an ingenerate in Electrical from University of Annaba, a Master in Electrical Research Network from the Ecole Polytechnique of Montreal, CANADA, and a PhD in Electrical Engineering from the University Mentouri Constantine. His research activities focus on Dispersed Generation; Analysis of different types of problem quality of electric power caused by renewable energy sources; Various techniques for optimizing the optimal power flow; Stability of groups; Power flow method for DC networks integrated into AC. 